\title{
Multiple Interpretations of EFL Learners' Silence in the Iranian Context
}

\author{
Reza Ghaffar Samar \\ Tarbiat Modares University of Tehran, Iran \\ E-mail: rgsamar@modares.ac.ir \\ Elham Yazdanmehr \\ Tarbiat Modares University of Tehran, Iran \\ E-mail: e.yazdanmehr@modares.ac.ir
}

Received: 13-06-2013

doi:10.7575/aiac.ijalel.v.2n.6p.15
Accepted: 26-07-2013

Published: 01-11-2013

\begin{abstract}
Attention to silence as part of the communicative discourse was first drawn in Sack's (1974) paper, in which it was perceived as a linguistic and communicative form, and from the functional point of view as capable of expressing ideational, interpersonal, and textual functions. Awareness of multiple functions of silence including the referential, emotive, conative, phatic, poetic and metalanguage is of greater significance when it comes to language learning settings, where learners from a different cultural background from the target language are present to learn that language. In such contexts, awareness of various functions of silence and correct interpretation of it is essential in teacher-student rapport. This paper aims to, first, provide an introduction to the multiple functions of silence in general and then to investigate these functions in EFL classes of Iran's private language institutes. The researchers' own teaching experience along with class observations and 2 phases of interview with teachers of those classes comprise the research data. Findings were indicative of teachers' lack of awareness of diverse communicative functions of silence in class and that this awareness could be raised through the informal interview phases. This paper attests to the fact that not all learner's silence should be interpreted negatively as lack of attention or knowledge. Teachers need to be aware of the salient meanings of silence in their EFL class and take an appropriate reactive step accordingly.
\end{abstract}

Keywords: silence, Jakobson's communicative model, culture, EFL, Iran

\section{Introduction}

Silence is sometimes louder than any utterance. Carrying with it a multitude of meanings, it serves to function differently in various national and cultural settings. What is common among multifarious descriptions of silence in linguistics is the functional, active and communicative roles attributed to it which distinguishes 'eloquent silence' from the simplistic view of the mere absence of talk. To characterize silence as eloquent means to see it as part of communication.

Silence found its way into linguistics through two main gates. The first was affected by philosophy along with literature. It cast a functional and pragmatic perspective at eloquent silence; however, this approach did not have a direct effect on the discipline. The other gate was acoustics through which silence was indicated as a topic of investigation. Within this paradigm, silence as a subject grew along two major directions one of which was the time-based examination of speech. The other direction, actually taken around the same time, deemed to be discourse analysis (Ephratt, 2008).

From the functional point of view, silence is considered as a linguistic and communicative form capable of expressing ideational, interpersonal, and textual functions. Various areas and domains for the study of silence are reviewed by Jaworski (2006). In the present study, however, the model employed to analyze the functions of silence is Jakobson's (1960) classic model of communicative functions of language which is well-known in linguistics as well as other disciplines.

\subsection{Jakobson's communicative model of language}

As Ephratt (2008) puts it, the Russian-American linguist Jakobson (1960) developed this model from the model proposed by Buhler (1934) which was comprised of three components of the procedure of verbal communication: referent (which resides in the outer world as the $3^{\text {rd }}$ person); speaker $\left(1^{\text {st }}\right.$ person speaking) and listener (the $2^{\text {nd }}$ person). Jakobson augmented three other tools of communication referring to both the outer world and to language and two components from the domain of language: the message and its organization, and the code as the object of rapport. Examine figure 1: 


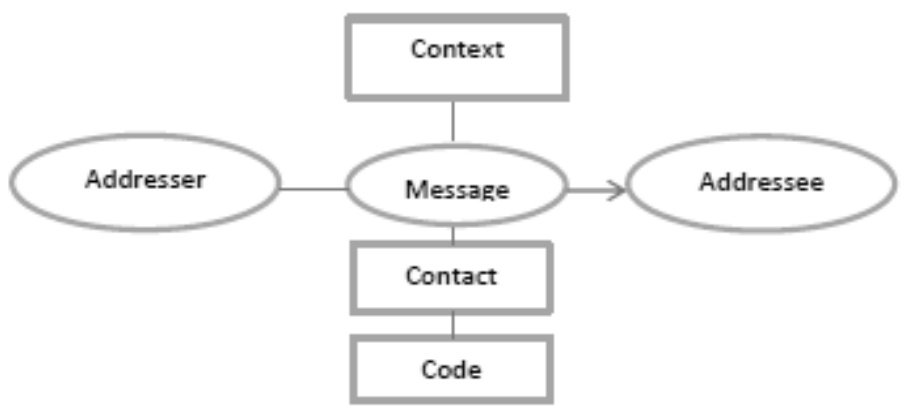

Figure 1. Factors determining functions of language (Jakobson, 1960)

Every one of these six components plays a role in the communication stream. However, in every communicative event just one is noticeable. This salience determines the communicative function of the given event. These constituents are described by Jakobson in Sebeok (1960) comprehensively:

\subsubsection{Emotive function (also known as 'effective')}

This function focuses on the speaker and intends to directly express the addresser's opinion and stance towards the topic of speech. It aims to create a feeling or impact of a particular emotion either true or pretended.

\subsubsection{Conative function}

This is oriented to the hearer and has its best grammatical manifestation in 'vocatives' along with 'imperatives' that syntactically, morphologically and even phonemically diverge from other nominal and verbal groupings. A linguistic instance would be: "Come here."

An instance of silence with this aim: silence to offer the floor to the interactant in turn taking.

\subsubsection{Poetic function}

The poetic function of language is the set towards the message for its own sake. This function cannot be comprehensively studied without the general problems of language and also the examination of language needs a complete consideration of its poetic function. An example of language used with this function is the word: "Smurf"

An example of silence used with this function: using silence in verses of poetry to create a gap for reader's contemplation.

\subsubsection{Referential function}

This function is mainly related to the element of 'context' and represents a situation, object or mental condition. Statements characterized by this function may include both definite descriptions and deictic terms.

A linguistic example would be: "The earth is round."

An example of silence with this function: In a Christian wedding when the priest asks the crowd for any protests, the crowd's silence implies they have no protests.

\subsubsection{Phatic function}

This function refers to 'language for the sake of interaction'. So, it is related to the element of 'contact'. Some messages mainly aim to establish, continue, or terminate communication, to examine if the channel is active. It is this function of language that is mutual between animals and the human race. For instance: "Hello?" (in the middle of conversation to make sure that the interlocutor is listening.)

Use of silence with this function: the silence between intimates

\subsubsection{Metalingual function}

It is the employment of language (what Jakobson prefers to call 'Code') for describing or analyzing itself. Its core element is the code: viewing language not as a tool but as the end-the goal of study. An example of this kind is: "What do you mean by krill?"

An example of silence with this function: when a stranger speaking an extrinsic language approaches you and asks for something, you cannot communicate and your lips remain sealed. This silence means: "I do not understand".

Every one of the factors in figure 1 is the core of a focal link or function that exists between the message and that factor. This gives us the six functions described above. This relationship can be demonstrated as the following:

Table 1. Factors of communication along with the functions of language (Hebert, 2011)

\begin{tabular}{cccc}
\hline Target factor and function no. & Target factor & Source factor & Function \\
\hline 1 & Context & Message & Referential \\
\hline 2 & Addresser & Message & Emotive \\
\hline 3 & Addressee & Message & Conative \\
\hline 4 & Contact & Message & Phatic \\
\hline 5 & Code & Message & Metalingual \\
\hline 6 & Message & Message & Poetic \\
\hline
\end{tabular}




\subsection{Purpose of study}

Considering the multifarious interpretations of silence in academic setting, this study seeks to answer the following question:

RQ: What communicative functions (as defined in Jakobson's model) do the instances of student's silence serve in Iranian EFL context?

\section{Review of literature}

Before 1970s, the majority of studies on silence focused on chronometric analysis of speech. Such studies as GoldmanErsler (1958) and Chapple (1939) produced quantitative predictions of the ratio of speech to non-speech. During 1970s, the core body of research on silence were correlated with negativity, passiveness, and powerlessness. Silence was treated as the non-existance of speech, and lack of meaning and purpose. Such studies included Hawkins (1971) and Bruneau (1973).

In the following decade, linguists carried out projects and released writings on particular sub-topics of eloquent silence. Researchers such as Dauenhauer (1980) viwed it top-down, that is not as an exclusively linguistic object but merely as an exmple of another object. Consequently, eloquent silence was treated from outside.

It was in the 90s that there was a growing interest in pragmatics and the linguistic study of eloquent silence saw a big transformation, from ground to figure. Such studies included Bilmes (1994), concerning relevance theory and Kurzon (1998), Salih \& Athamneh (1995) on translating eloquent silence (cited in Ephratt, 2008).

Studies on multifarious functions of silence in different cultures pervaded late 20th century and all through the contemporary era. Jones (1999) investigated non-native English speaking students' participation in classroom group discussions. He found that the students' reticence and difficulty of active participation in discussions had cultural roots. This study showed how silence functions and signifies differently in different cultures.

Ling (2003) examined the theoretical texts pertaining to silence and showed how silence functioned in various domains of human communication in different cross-cultural settings. This study suggested that to enhance better interpersonal/cultural communication, along with promoting the quality of communication, we need to promote more awareness of the multiple interpretations of silence and also more consideration of the multiple communicative functions in different social and cultural settings.

Another study concerning the role of silence in academic settings was carried out by Hu \& Fell-Eisenkraft (2003). This research included immigrant Chinese students' perceptions of their own silence in language arts class along with the authors' discussion of the cultural manifestation of these students' attitudes from their own viewpoint as cultural insiders. A couple of suggestions were made to essentially assist the learning of these students.

In another qualitative study carried out by Nakane (2006), functions of silence were studied in classroom interactions between Asian and Australian students. The vast use of face-saving silences by Japanese students was observed to be negatively assessed by Australian professors whose response techniques led to the lack of empathy. This study also found that silence might be settled when shifts happen in the participants' attitudes towards the footing of their interactants.

Ephratt (2008) gave a comprehensive analysis of functions of language in Jakobson's model. Initially, he distinguished between pauses and eloquent silence which he considered to be a linguistic sign, and then elaborated on the roles of eloquent silence within Jakobson's model. This study was truly inspirational for the present paper. Ephratt (2011), in an extension of his previous work, offered his pragma-linguistic model to categorize and map various silences and shed light on the relation of silence and speech.

Among the ethnographic studies of silence, mention can be made of Mushin \& Gardner (2009) who presented a conversational analysis of silences in speech. The comparison they made was between American and Anglo-Australian discourse. Their findings were indicative of differences between the length and tolerance of silence between the two cultural backgrounds.

The most recent research published on communicative functions of silence has been carried out by Ephratt (2012). In this research, silence is analyzed on the basis of Grice's cooperative principle. It is indicated that, similar to speech, verbal silence might occasionally help communication, thereby obeying the cooperative principle, and at times defies it. These findings reveal the significant role that verbal silence plays in communication.

In the Iranian context, we are encountered with a dearth of research into the potential meanings of learner's silence especially in the realm of learning EFL. It is hoped that the present paper acts as a pioneering work along this path of inquiry.

\section{Methodology}

3.1 Participants

10 instructional sessions of 10 EFL classes were observed in a well-known private language institute in Mashhad, Iran. The students were 75 in number and were all at the intermediate level of language proficiency. They were female adult language learners in 18-40 range of age. They shared the same cultural background (Iranian) and mother tongue (Persian).

The 10 teachers whose classes were observed and were later interviewed were all female and their job experience ranged between 3-10 years. They aged between 22 and 30 and were of the same cultural background and native language, respectively Iranian and Persian. Their participation was voluntary and they were informed of the purpose of this research. 


\subsection{Instrumentation}

The data were gathered mainly from three sources: interview with teachers, observation of their classes and the researchers' own teaching experience. No pre-designed instruments were employed to measure learners' performance.

\subsection{Procedures}

This research was carried out in spring 2012. The interview was carried out in 2 phases, once before the new term began, and another time after the term was finished. The aim of the first interview was to investigate teachers' perception of students' silence generally and in advance to getting familiar with Jakobson's communicative functions. The second interview was after the teachers passed a whole intermediate term and, aware of the communicative functions of silence, paid attention to students' silences in their classes.

\subsubsection{Interview phase 1}

(Dated: May 4th, 2012) We initially, held group interviews with colleagues in the friendly environment of the teachers' room. This interview was discussion-based and since the interviewer and the interviewed teachers were colleagues, they could share their points of view in a relaxed and intimate manner. These group interviews were done in two sessions, once with a group of 4 and another with a group of 6 colleagues (This was because all these colleagues were not available together at the same time). The structure of the interview was as follows:

1) Drawing the group's attention to the notion of learners' silence in class, with questions such as:

Have you ever noticed instances of students' silence in your class?

2) Examining what the teachers usually attributed this silence to, with questions like:

In what cases and for what reasons do you think students tend to keep silence?

3) Asking what they usually do when they face their students' silence. Sample question:

Do you go along with a student's reticence, or think of ways to reduce it?

4) Familiarizing teachers with communicative functions of silence, namely referential, conative, emotive, metalingual, phatic and emotive

5) Demanding that they pay more attention to instances of learners' silence in their classes during the forthcoming term to see which types were more prevalent: They were recommended to write down the instances of each type of silence that they would observe in their students. This was to be used in their final analysis.

\subsubsection{Interview phase 2}

(Dated: June 21st- 22nd, 2012) This phase was done when the term, which lasted for one and a half months, was finished. Teachers had this opportunity to pay more attention to instances of learners' reticence in their classes, were to classify them and discuss them in this phase of interview.

The teachers were met in three sessions, based on availability: 3 of them were met on June 21 st morning, 4 in the afternoon, and the rest were met the following day. First they were asked how it all went, and were then invited to share their judgments and overall ratings with the interviewer and in the presence of the group. Each talked about the instances of students' silences that they encountered in class for each function, and explained the details. Finally, each teacher sequenced the functions in the order of saliency/dominance in her class(es).

\subsubsection{Class observations}

One session of every teacher's class was attended and observed by the observer researcher. 10 sessions on the whole were observed in this research. During this observation the demographic features of each class were registered including the number of students, their names and characteristics of students (age, gender, and educational level). In these 10 sessions, the researcher jotted down the instances of students' silences observed along with the names of those students. These observations would be used in the 2 nd phase of the interview accompanied by and discussed among the teachers and the researcher.

\section{Results and discussion}

As previously mentioned, the aim of the first phase of the interview was to: draw teachers' attention to the subject of this research, to see the extent to which they generally notice students' silence in class, familiarize them with the targeted communicative functions of silence in class, provide them with an opportunity of 1.5 months, to pay informed attention to instances of each type of silence in class and finally rate these functions in the order of saliency and dominance in the Iranian EFL context.

What we found from this phase was that:

1- All these teachers had the experience of facing various instances of learners' silence in class.

2- Although they all experienced students' silences, they had hardly ever distinguished them in their mind or attributed them to different functions.

3- They mostly (not in all cases) viewed learners' silences as a negative sign of incompetence, lack of interest or inattentiveness.

4- Their reaction to their students' silences had been to push them into speech, and in case it had not worked they tended to lose mark.

5- They were all surprised by and then interested in learning about the 6 communicative functions of silence since none had heard about them before.

6- Upon learning about communicative functions of silence, the teachers tended to rethink about their wholly negative perception of their students' silences. They seemed eager to be back in class and pay informed attention to their students' silence and see to which type each belonged. 
The second phase of the interview was done after one term when the interviewer researcher and her colleagues met again. This second interview took naturally longer than the first one and its discussion-based format helped the most fruitful results to be achieved. The participants had a lot to say, and most evidently they seemed very interested and motivated to share their experiences and opinions about the topic.

Initially they were asked to offer their ratings of the functions of silence in terms of dominance in their classes. Their initial judgment was rather divergent although they agreed that emotive and referential were the most frequent types. After sharing instances of each type, however, the following ordering was the consensus:

Emotive $>$ Referential $>$ Conative $>$ Phatic $>$ Metalingual $>$ Poetic

Emotive function:

This function generally has its origin in the speaker and the speaker's expression of feeling and emotion. As far as eloquent silence is concerned, the emotive function is its least disputable function of all. All researchers of eloquent silence, attest to the existence of the emotive force of silence (Ephratt, 2008). The most salient cases of this type of silence which the teachers witnessed in their classes were the following:

1- Silence expressive of attention and respect: Here, the students' silence is indicative of attention and respect for the teacher and the class. More importantly, it is perceived as the unmarked sign of understanding since it is commonly expected that if a student does not understand part of the lesson being taught, s/he tends to break that silence, raise hand and ask questions. Therefore, this form of silence is commonly valued by teachers and perceived as positive.

2- Silence expressive of unpreparedness, fear or shame: This happens when a student is not well prepared for class or has not done the homework and prefers to keep silent. This sort of silence can also be the result of feeling ashamed of talking or participating, again because one feels unprepared. Moreover, this can be mixed with a feeling of fear of being wrong, or perceived as incompetent, or even laughed at.

3- Silence expressive of dislike: This occurs when a student dislikes the topic, the task or the interactant(s). Lack of interest, evidently, acts as a demotivating factor to participate in class activities especially class discussions. Awareness of this type of silence is essential for teachers since it impedes them from attributing a student's reticence necessarily to lack of knowledge.

4- Silence expressive of sadness or demotivation: There can be different reasons for this including sickness, boredom, physical exhaustion, etc. An ostensible example can be when a student, having heard his/her disappointing quiz results, becomes temporarily reticent.

Referential function:

As stated previously, the most direct and ostensible function of language is to convey information about a fact of the world. Some scholars believe that this function can merely be served through language. Ephratt (2008), however, indicated that eloquent silence can be as well indicative of conveying such information. A very common instance of such silence is when it is used efficiently by an individual implying the unmarked answer. The example of the Christian wedding was formerly mentioned. In EFL classes, the teacher participants in this research reported the most prevalent cases for referential function as in:

1- Calling the roll: This could be the commonest among all classes, since it was experienced every single session. Whenever the teacher, at the beginning or the end of the class time, called the roll, the unmarked answer of the students who were present was simply silence. The marked case was when somebody was absent or late which made classmates to inform the teacher. Examine this conversation (Truly it is a conversation, since the learner's silence is interpreted as a positive response and not merely a blank! It is comparable to the example of the Christian wedding):

T: "Everybody present?" OR "Did I read all your names?"

Ss: - . - . - . - - (implying: "Yes, we are." OR simply "Yes.")

2- Giving class assignments: This occurs when the teacher demands students to do a particular task or activity, individually, in pairs or as a group. Here, the students' silence in response, is the unmarked indication of accepting to do the task and compliance. Examine the following conversation:

T: "Now, can you do it in pairs this time?"

Ss: - - - - - . - - (implying: "Yes, we can." OR "We will.")

3- Comprehension checks: This happens when the teacher, having taught a particular point, wants to make sure that the students have got it and have no problems or questions. Learners' silence in response is perceived to be the unmarked sign that they have no problems. This can also occur when the students are asked to read the instructions of an exercise, task or question either in the book or an exam. In these cases, students' silence is generally perceived by teachers as a sign of their understanding the instructions and having no problems with that. Read the following conversation:

$\mathrm{T}$ (after explaining a grammatical point faces the students): "OK. Any problems?" OR "Any questions?"

Ss: - . - . - . - . - - (implying: "No, we haven't. "OR simply "No.”)

Conative function:

This is the function whose orientation is towards the addressee. The best linguistic case would be imperatives which put the task on the shoulders of the hearer. Dissimilar to the referential function, speech (or silence) here does not apply for Yes/No assertions, but instead concerns the addressee, or serves in itself as a speech act. The most prevalent instances of this type of silence in an EFL class were reported as the following: 
1- Turn-taking: The most salient manifestation of conative function is in turn-taking in conversations. Here, within the conversation, when one interactant wishes to give the floor to her interlocutor, the commonest tool she employs is a brief silence. Having perceived this silence as an offer to speak, the interlocutor knows it is her turn to take the floor. The following example is part of a conversation observed in one of the EFL classes. Students were busy in pair work discussing what they did during their last holiday:

S1: We went to Torghabe, me and my family...we stayed for the noon and then came back. The weather was just what everybody wished - - - -

S2 (noticing that now she is expected to take the floor): Aha...good. Well, we do not usually go out. We stayed home. I just had TV to watch and - - - -

S1: You mean you never go out on the weekend? So different from us!

S1 and S2 (laugh together)

2- Giving the first floor: What is implied by this is the offer to begin the conversation. This function is very common in the Iranian culture. When there is something to talk about, usually the interactants offer each other to begin the conversation. This is a sort of what is called ta'arof in Iranian culture and is perceived as a facesaving act. Teachers' perception of this function of silence was not negative generally. They were understanding of this function and found it also prevalent in their first language conversations. The researchers' observation of EFL classes in this study found instances of this, one of which is presented here. In this example the students were asked to work in pairs and work on the discussion questions in their textbook.

S1 and S2: - - - - - . - (brief initial silence of the two students)

S1 (with a smile): You start please.

S2: OK. I don't think this can be done in our country. Our people can never ....

Phatic function:

As formerly explained, this function deals primarily with establishing, prolonging, continuing, or discontinuing conversations. Sometimes it operates when you want to make sure that the channel is open. In the middle of conversation, for instance, you can address your interlocutor by: "Hello, do you hear me?" This is, however, a linguistic function. Silence is also capable of serving such function. The following cases were witnessed by EFL teachers in this study:

1) Using silence to let the conversation carry on: When two (or more) people are involved in a conversation and one is talking, the listener's silence accompanied by keeping eye-contact (and in some cases gestures such as nodding) allows the speaker to continue his speech. This type of silence occurs at the same time of the other person speaking and is not in advance of or subsequent to the speech.

2) Using silence to discontinue conversation: Prolonged or too frequent stretches of silence within a conversation impedes its development. It can be due to diverse reasons. The function, however, is to discontinue the discussion or speech. An instance of such silence happened when a student was asked a too personal question by her partner in pair work. She disliked to answer and preferred to be silent. Upon noticing this, her partner quickly changed the topic. In this case this function served emotive function as well.

Metalingual function:

In this function the central component is the code (the language), i.e. when you use language to mention something about language, its structure or comprehensibility. According to the literature and EFL teachers' perceptions in this research, silence as well can be used to serve the metalingual function. As the teacher participants in this study witnessed, silence serving this function was more prevalent in classes of lower proficiency levels. At the intermediate level, such instances were rare but existent. The following are the cases in which silence is usually used with metalingual function in EFL classes:

1- Code as the object: This includes cases in which labguage is the object of the speech. In an EFL class, if you as a teacher address a student and ask him something beyond his current proficiency level, he might get silent simply because he has not got what you said. This silence means: "I cannot understand what you are saying.", "I cannot understand your language." OR "I cannot communicate." This can happen for reasons other than lack of proficiency. Examine this instance that was witnessed by one of our teachers. The teacher addresses a student suddenly and says something very fast. The abrupt and fast address reduces the content's comprehensibility. The student unable to respond keeps silent. Noticing this, the teacher repeats herself a second time. She exactly repeats what she has just said but this time slower. To this the learner is able to answer eligibly.

2- Silence as a syntactic marker: This is mostly common when as a result of lack of competence a learner tends to eliminate some syntactic element in her speech. Here, the instances of silence are very short and more like pauses during the speech, omission of some parts due to lack of competence. A very common example which was witnessed by all our teacher participants was the learners' omission of articles in their speech. It is not always like this that they do not know that an article is needed. Mostly because they doubt which article (definite or indefinite) is appropriate they prefer to omit it wholly. The little pause they usually insert before nouns in their speech can be for this reason.

Poetic function:

At the core of this function lies the message in its own right. This function is mainly for the aesthetic influence caused by language. Silence serving poetic function is employed in poetry and literature the instance of which was previously mentioned. Our teacher participants witnessed no cases of student's silence with this function in their EFL classes. The 
researchers' observations obtained none, either. It does not, however, imply that this function is totally absent in EFL classes. One such case that can be thought of (and actually witnessed by the observing researcher in her own EFL classes) is the use of silence in learners' dramatic performance of their textbook dialogues with each other. Of course these performances are rather mechanical since students listen to the conversations and then try to imitate the tone and pronunciation while they perform them dramatically in pairs or groups together. Their dramatic performance is far from authentic, but anyway they have to imitate pauses and silences in the original listening track which are vital characteristics of natural human speech.

Observation of the EFL classes in this study corroborated the dominance of communicative functions of learners' silence in the order recognized by the teachers. Moreover, a couple of additional issues were recognized which were not directly related to communicative functions but to the general tendency of a student to be reticent. One such issue was the relationship between learner's age and silence. It was observed that learners who were outliers in terms of their age in class were generally more reticent than the others. For instance in a class where the majority of students were between 20-30 years of age, a student who was 60-and-so years old was outstandingly less cooperative than others in class. She was never the opener of conversations. Her responses were short and soon kept silent to give the floor to her partner(s). Interestingly, in another class where the majority of students were adult learners of English, a teenage student was perceived the most silent girl in class, although the teacher was well aware that she was by no means less proficient than her classmates.

Besides the age factor, the student's educational level appeared to be involved in the students' overall reticence. In the observations it appeared that learners whose educational level was lower compared to their classmates, tended to be more reticent. Self-esteem could be hypothesized to be the mediating factor here. This study does not aim to claim any causal relationship. Even for claiming a correlation, more extensive studies are required. These were merely factors that were noticeable in the observations. Further research is welcomed to delve into the true nature of relationship and then possibly the causal relationship.

\section{Conclusion}

This study aimed to examine EFL teachers' perception of the communicative functions of their students' silence in class. Since we as the researchers are also EFL teachers, our observations of EFL classes along with 10 of our colleagues' group-based interviews were used to find the dominant functions of learners' silence in class. Among the communicative functions of language proposed by Jakobson (1960) which were later applied to silence as well by Ephratt (2008), some were reported by teachers to be more dominant in the Iranian EFL context. Teachers' rating which was corroborated by our observations yielded this order of dominance:

\section{Emotive $>$ Referential $>$ Conative $>$ Phatic $>$ Metalingual $>$ Poetic}

All the teachers had experienced silence on their students' side, but had been unaware of diverse communicative functions which can be served by silence. In the first phase of interviews they were familiarized with these functions and were more enthusiastic to participate in this study. The point which is aimed to be made is that awareness of these functions is necessary for teachers. Not all instances of learners' silence is to be interpreted as an evidence of lack of knowledge or incompetence. Particularly when it comes to learning a second language, learning conditions become further tense and necessitates adequate understanding on the part of the teacher.

Besides the issues witnessed in class observations such as age and educational level (and possibly any other intervening factor) which can be investigated in relation to learners' overall reticence, there is another area which is open to further research. In this study we focused on learners' silence and different functions that it could serve. In similar vein, teacher's silence and its diverse functions in EFL context can be studied. Learners' attitudes towards their teacher's silence can be investigated along with their multiple interpretations. Knowledge of all this sheds light on what actually takes place in class environment in teacher-learner or learner-learner interactions. What is common in all these suggestions for further research is the belief that eloquent silence is louder than any words uttered and is an area as worthy of attention, if not greater, in the quality and success of communication. Now, we wish to end this paper with this quotation to be kept in mind:

“The most profound statements are often said in silence." Lynn Johnston (1947), For Better or for Worse.

\section{References}

Bruneau, T. J. (1973). Communicative silences: forms and functions. The Journal of Communication 23, $17-46$. http://dx.doi.org/ 10.1111/j.1460-2466.1973.tb00929.x

Chapple, E. D. (1939). Quantitative analysis of the interaction of individuals. Proceedings of the National Academy of Sciences of the United States of America (PNAS) 25 (2), 58-67. http://dx.doi.org/ PMC1077712

Dauenhauer, B. P. (1980). Silence - The phenomenon and its ontological significance. Bloomington: Indiana University Press.

Ephratt, M. (2011). Linguistic, paralinguistic and extralinguistic speech and silence. Journal of Pragmatics 43. 22862307. http://dx.doi.org/ 10.1016/j.pragma.2011.03.006

Ephratt, M. (2008). The functions of silence. Journal of Pragmatics 40. 1909-1938. http://dx.doi.org/ 10.1016/j.pragma.2008.03.009 
Ephratt, M. (2012). "We try harder" - Silence and Grice's cooperative principle, maxims and implicatures. Language and Communication 32, 62-79. http://dx.doi.org/ 10.1016/j.langcom.2011.09.001.

Goldman-Ersler, F. (1958). The predictability of words in context and the length of pauses in speech. Language and Speech 1, 226-231. http://dx.doi.org/ 10.1111/j.1460-2466.1961.tb00334.x

Hawkins, P. R. (1971). The syntactic location of hesitation pauses. Language and Speech 14. 277-288. http://dx.doi.org/10.1177/002383097101400308

Hebert, L. (2011). The functions of language. Retrieved from http://www.signosemio.com/jakobson/functions-oflanguage.asp

Hu, Y., \& Fell-Eisenkraft, S. (2003). Immigrant Chinese students' use of silence in the language arts classroom: perceptions, reflections, and actions. Teaching and Learning 17(2). 55-65.

Jakobson R. (1960). Closing statement: linguistics and poetics. In T. A. Sebeok (Ed.) Style in Language. New York: Wiley.

Jaworski, A. (2006). Silence. Encyclopedia of language \& linguistics (2nd Ed.). pp. 377-379.

Jones, J. F. (1999). From silence to talk: cross-cultural ideas on students' participation in academic group discussion. English for Specific Purposes 18(3). 243-259. http://dx.doi.org/ 10.1016/S0889-4906(97)00059-8

Ling, W. N. (2003). Communicative functions and meanings of silence: an analysis of cross-cultural views. Retrieved from http://www.lang.nagoya-u.ac.jp/bugai/kokugen/tagen/tagenbunka/vol3/wong3.pdf

Mushin, I., \& Gardner, R. (2009). Silence is talk: conversational silence in Australian Aboriginal talk-in-interaction. Journal of Pragmatics 41. 2033-2052. http://dx.doi.org/ 10: 2033-2052.

Nakane, I. (2006). Silence and politeness in intercultural communication in university seminars. Journal of Pragmatics 38. 1811-1835. http://dx.doi.org/ 10.1016/j.pragma.2006.01.005

Sacks, H.; Schegloff, E. A., \& Jefferson, G. (1974). A simplest systematics for the organization of turn-taking for conversation. Language 50. 696-735.

Trent, M. (2010). Communication. Retrieved from http://www.lulu.com/shop/mel-trent/communication/ebook/product18594900.html. 